\title{
Recurrent pericarditis: an update on diagnosis and management
}

\author{
Alessandro Andreis ${ }^{1} \cdot$ Massimo Imazio $^{1}$ (1) $\cdot$ Matteo Casula $^{1} \cdot$ Stefano Avondo ${ }^{1} \cdot$ Antonio Brucato $^{2}$
}

Received: 24 November 2020 / Accepted: 11 January 2021 / Published online: 28 February 2021

(c) Società Italiana di Medicina Interna (SIMI) 2021

\begin{abstract}
Recurrent pericarditis is a true challenge for clinicians, especially when the patient becomes unresponsive or not tolerant to conventional treatments. An accurate diagnosis of recurrent pericarditis, possibly supported by advanced imaging tools, is critical to provide timely and appropriate treatment of symptoms and prevention of further episodes. The incessant research on the inflammatory pathways underlying cardiovascular diseases, led recently to the assessment of anti interleukin-1 agents in the setting of recurrent pericarditis. This review will focus on the diagnostic assessment of recurrent pericarditis, along with the most modern therapeutic advances in this field. Bibliographic databases were searched (MEDLINE/PubMed, BioMed Central, the Cochrane Collaboration Database of Randomized Trials, Scopus, ClinicalTrials.gov, EMBASE, Google Scholar) using the terms "recurrent pericarditis" AND "diagnosis" OR "treatment" OR "IL-1" OR "inflammation".
\end{abstract}

\section{Introduction}

Acute and recurrent pericarditis are caused by an active inflammation of the pericardium, which is idiopathic in most cases. Acute pericarditis is the most frequent among pericardial syndromes and accounts for about $5 \%$ of all Emergency Department admissions for acute chest pain [1]. The most frequent complication after acute pericarditis is recurrent or incessant pericarditis, reported in about $15-30 \%$ patients. This rate may rise up to $50 \%$ in case of previous recurrences, patients who previously received corticosteroids or patients with a non-idiopathic (e.g., bacterial, neoplastic) etiology [2-4].

Despite a generally good prognosis, recurrent pericarditis ensues a negative impact on patient' quality of life and still represents a true challenge for clinicians, especially when the patient becomes unresponsive to conventional treatments $[5,6]$.

A decade ago, large trials demonstrated the dramatic effect of colchicine, capable of halving the risk of further

Massimo Imazio

massimo_imazio@yahoo.it

1 Division of Cardiology, Department of Medical Sciences, Città Della Salute E Della Scienza Di Torino Hospital, University of Torino, Corso Bramante 88, 10141 Torino, Italy

2 University of Milano Statale, Milano, Italy recurrences $[2,4,7,8]$. In the last few years, the growing interest towards the complex inflammatory pathways underlying recurrent pericardial inflammation led to the identification of newer biologic drugs such as interleukin-1 inhibitors, which are currently showing promising results [9].

A correct clinical management of pericarditis is key to avoid subsequent recurrences. This review will focus on the diagnostic assessment of recurrent pericarditis, along with the most modern therapeutic advances in this field.

\section{Methods}

A literature review has been performed including studies published up to August 2020. Bibliographic databases were searched (MEDLINE/PubMed, BioMed Central, the Cochrane Collaboration Database of Randomized Trials, Scopus, ClinicalTrials.gov, EMBASE, Google Scholar) using the search terms "recurrent pericarditis" AND "diagnosis" OR "treatment" OR "IL-1" OR "inflammation". The research was restricted to English language. Two authors (AA, MI) independently screened titles and abstracts of all studies, while potentially eligible studies were appraised as full text. The most relevant papers cited in the studies and in international guidelines were also screened. 


\section{Definitions}

Pericarditis is defined as "recurrent" in case of relapse after a minimum symptom-free interval of 4-6 weeks. In case of an earlier relapse or either persistence of symptoms for $>4-6$ weeks after the acute episode, pericarditis is defined as "incessant". This interval of time has been established according to the approximate duration of common anti-inflammatory treatments, tapering included [5]. Pericarditis is defined as "chronic" in case of duration $>3$ months [10].

\section{Etiology search: not always needed}

Pericarditis is usually ( $>80 \%$ ) idiopathic, except in developing countries, where Mycobacterium Tuberculosis is responsible for most cases (70\% in sub-Saharan Africa) [11]. Indeed, in developed countries Mycobacterium tuberculosis can be recognized as the etiological agent in less than $5 \%$ cases [12]. Other non-infectious causes of pericarditis include auto-immune diseases, autoinflammatory diseases (including cryopyrin-associated periodic syndromes, familial mediterranean fever, tumor necrosis factor receptor-associated periodic syndrome, Still disease), post-cardiac injury syndromes, cancer [13-15]. Pericarditis etiologies have been reported in Table 1.
Some clinical features at the time of clinical presentation are considered "red flag" warnings, predicting a nonidiopathic etiology or an increased risk of complications: subacute course (HR 3.97), fever $>38^{\circ} \mathrm{C}$ (HR 3.56), failure of aspirin or of nonsteroidal anti-inflammatory drugs (HR 2.50), large effusion or cardiac tamponade (HR 2.15), female gender (HR 1.67) [16]. This latter, gender-related feature, however, has been appraised in various studies with contradictory findings $[17,18]$. Additional presumptive indicators of a worse prognosis, according to experts' opinion, include immunodepression, trauma, myopericarditis, oral anticoagulant therapy [19, 20]. In the absence of these features and when a specific cause is not evident at first clinical assessment (medical history, physical examination, 12-lead ECG, echocardiography, chest X-ray, routine blood tests), the patient is considered at low risk for complications, and may be, therefore, prescribed an empirical antiinflammatory treatment and followed-up outpatient. In this clinical scenario, the etiology is considered "idiopathic" or deemed of viral origin and further diagnostic tests are usually not required, since they would not change the therapeutic approach [21, 22]. However, when one or more of the high-risk features are present, a full etiology search is useful, since it may reveal an unknown underlying disease, whose diagnosis could be critical for an effective, causal treatment of pericarditis (Table 2). In the presence of one or more minor risk features, the strategy is chosen upon clinician judgement with a case-by-case approach (Fig. 1).
Table 1 Pericarditis etiology

Systemic diseases

Neoplastic

Post-cardiac injury

Metabolic causes
Viral-common (parvovirus B19, EBV, CMV, HHV-6, enterovirus, coxsackieviruses, echoviruses)

Bacterial (Mycobacterium Tuberculosis, Coxiella burnetii, Pneumococcus, Meningococcus, Gonococcus, Streptococcus, Staphylococcus, Haemophilus, Chlamydia, Mycoplasma, Legionella, Leptospira, Listeria.

Fungal-rare (Histoplasma, Aspergillus, Blastomyces, Candida)

Parasitic_rare (Echinococcus, Toxoplasma)

Auto-immune diseases (systemic lupus erythematosus, sjogren syndrome, rheumatoid arthritis, sarcoidosis, scleroderma rheumatoid arthritis)

Autoinflammatory diseases (cryopyrin-associated periodic syndromes, familial mediterranean fever, tumor necrosis factor receptor-associated periodic syndrome, Still disease)

Vasculitis (Churg-Strauss syndrome, Horton disease, Takayasu disease,

Behcet syndrome)

Amyloidosis

Primary tumors-rare (mesothelioma)

Secondary tumors (lung cancer, breast cancer, lymphomas and leukemias)

Post-pericardiotomy syndrome

Post-myocardial infarction syndrome

Iatrogenic (transcatheter ablation, percutaneous coronary interventions)

Radiation

Trauma

Uremia

Myxedema

Anorexia nervosa

Drugs

Other
Aortic dissection, chronic heart failure, pulmonary arterial hypertension 
Table 2 Treatments for pericarditis

\begin{tabular}{|c|c|c|c|}
\hline & Starting dose & Duration & Tapering protocol \\
\hline Aspirin & $750-1000 \mathrm{mg}$ every $8 \mathrm{~h}$ & $1-2$ weeks & $\begin{array}{l}\text { Decrease doses by } 250 \mathrm{mg} \text { every week } \\
\text { (stop after } 4-5 \text { weeks) }\end{array}$ \\
\hline NSAIDs & $\begin{array}{l}\text { Ibuprofen } 600-800 \mathrm{mg} \text { every } 8 \mathrm{~h} \\
\text { Indomethacin } 25-50 \mathrm{mg} \text { every } 8 \mathrm{~h}\end{array}$ & $1-2$ weeks & $\begin{array}{l}\text { Decrease doses by } 200 \mathrm{mg} \text { every week } \\
\text { (stop after } 4-5 \text { weeks) } \\
\text { Decrease doses by } 25 \mathrm{mg} \text { every week } \\
\text { (stop after } 4-5 \text { weeks) }\end{array}$ \\
\hline Colchicine & $\begin{array}{l}0.5 \mathrm{mg} \text { twice daily (half dose } \\
\text { if }<70 \mathrm{~kg},>70 \text { years, intolerant to } \\
\text { higher doses or with impaired renal } \\
\text { function (eGFR } 35-49 \mathrm{ml} / \mathrm{min} \text { ) }\end{array}$ & $\begin{array}{l}3 \text { months (acute pericarditis) } \\
6-12 \text { months (recurrent pericarditis) }\end{array}$ & Not needed \\
\hline Corticosteroids** & Prednisone $0.2-0.5 \mathrm{mg} / \mathrm{kg}$ daily & $\begin{array}{l}1 \text { week (or until complete symptoms } \\
\text { resolution and normalization of } \\
\text { CRP) }\end{array}$ & $\begin{array}{l}>50 \mathrm{mg} \text { daily: decrease doses by } 10 \mathrm{mg} / \\
\text { day every week } \\
25-50 \mathrm{mg} \text { daily: decrease doses by } 5 \mathrm{mg} / \\
\text { day every week } \\
15-25 \mathrm{mg} \text { daily: decrease doses by } \\
2.5 \mathrm{mg} \text { /day every } 1-2 \text { weeks } \\
<15 \mathrm{mg} \text { daily: decrease doses by } 2.5 \mathrm{mg} / \\
\text { day every } 2 \text { weeks }\end{array}$ \\
\hline Azathioprine & $\begin{array}{l}1 \mathrm{mg} / \mathrm{kg} \text { daily (starting dose), then } \\
\text { increasing to } 2-3 \mathrm{mg} / \mathrm{kg} \text { daily ( } \max \\
\text { dose } 150 \mathrm{mg} / \text { daily) }\end{array}$ & Several months & Not needed \\
\hline $\begin{array}{l}\text { Intravenous } \\
\text { immunoglobu- } \\
\text { lins (IvIG) }\end{array}$ & $400-500 \mathrm{mg} / \mathrm{kg} /$ daily & 5 days (may be repeated after 30 days) & Not needed \\
\hline Anakinra & $\begin{array}{l}\text { 1-2 mg/kg daily (maximum } 100 \text { mg/ } \\
\text { day) }\end{array}$ & Several months & $\begin{array}{l}\text { Slow withrawal of treatment over } \\
3 \text { months or more }\end{array}$ \\
\hline
\end{tabular}

**Calcium and vitamin D supplementation is recommended

$C R P$ C-reactive protein
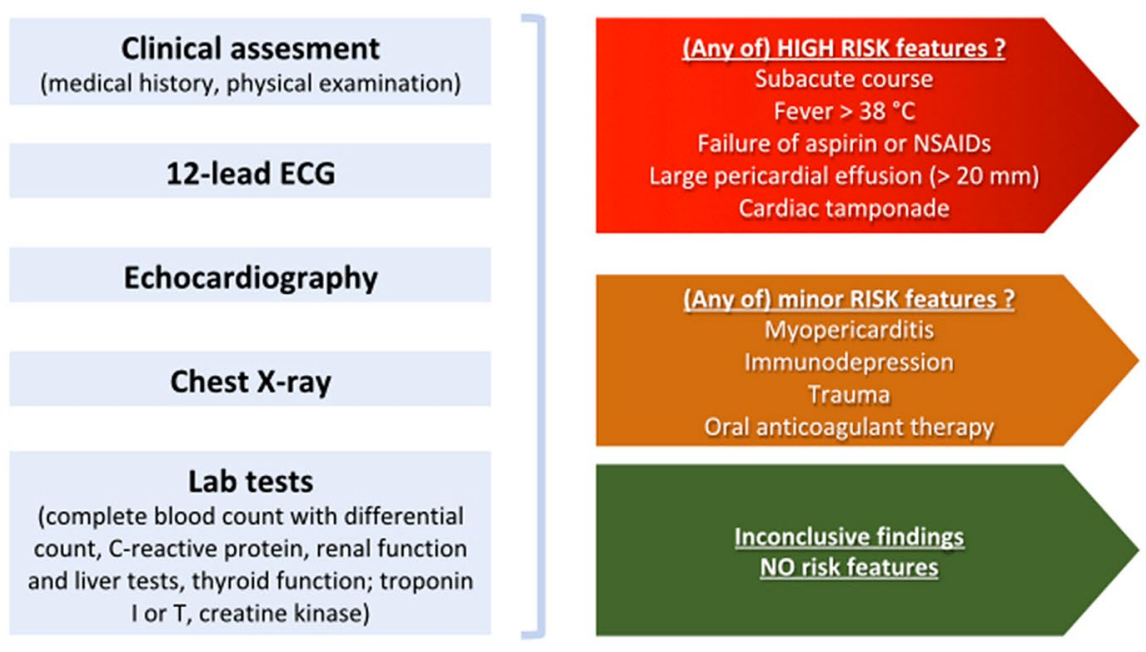

\section{High risk of non-idiopathic etiology or complications}

Full etiology search is useful

Fig. 1 Early diagnostic management

Idiopathic pericarditis has an overall good prognosis (Fig. 2) and the risk of cardiac tamponade $(<2 \%)$, chronic constriction $(<0.5 \%)$ or in-hospital death $(1.1 \%)$ is very low [6, 23-25]. However, a non-idiopathic etiology (especially tuberculous, purulent, neoplastic, autoimmune) has been associated with an high risk of recurrent pericarditis (57\% at 72 months) [25, 26], chronic constriction (8\%) and cardiac tamponade (up to $50 \%$ in patients with malignant effusions) 
Fig. 2 Complications
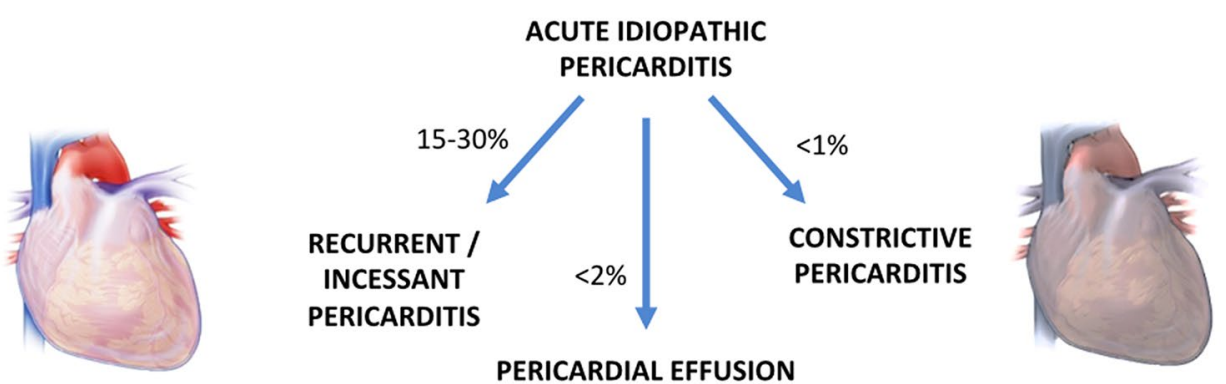

[25, 27, 28]. Moreover, chronic constriction is more frequent in patients with incessant pericarditis $(\mathrm{HR}=31)$, while recurrent pericarditis has never been demonstrated as a clear predisposing factor [5, 29].

A concurrent myocardial involvement occurs in $15 \%$ patients with pericarditis and usually does not affect the prognosis [30].

\section{Diagnostic challenges in patients with recurrent pericarditis}

Traditionally, the diagnosis of acute pericarditis is made in the presence of at least two of the following features: pericardial chest pain (sharp, infrascapular, worsened by breathing, improved by leaning forward), friction rubs, ST-segment elevation or PR-segment depression on 12-lead ECG, new or worsening pericardial effusion [10]. Increased C-reactive protein and second-level imaging tests such as cardiac magnetic resonance (CMR) may provide further confirmation (or exclusion) of pericardial inflammation in doubtful cases [31-33]. In fact, in the setting of recurrent pericarditis, patients usually display milder signs and symptoms on subsequent clinical presentations, making the diagnosis (and management) more difficult [34]. An observational study on 275 patients showed that about $10 \%$ patients with a previous diagnostis of acute pericarditis (mostly females or previously treated with corticosteroids) may complain of recurrent pain during the follow-up, without evidence of pericardial inflammation according to traditional criteria. However, in the same patients, an higher risk of recurrence was observed over a 40-month follow-up [35]. Given the uncertainties in the proper identification of recurrent pericarditis, currently available diagnostic tools such as CMR and CT provide further support and diagnostic accuracy [31-33].

CMR is a powerful diagnostic tool for pericardial diseases [11]. The identification of an increased signal intensity of the pericardium in short-TI Inversion Recovery-T2 weighted sequences associated with increased signal intensity on T1-weighted late gadolinium enhancement sequences is a strong clue of recurrent pericardial inflammation (AUC 0.86 if both features are present) $[36,37]$. Not only qualitative but also quantitative assessment of late-gadolinium enhancement of pericardium adds incremental diagnostic value over the conventional diagnostic criteria for pericarditis (AUC 0.80 versus 0.69 ) [37]. CMR may also show increased pericardial thickness, which can be due to an edematous pericardium or chronic pericardial constriction. In this latter situation, CMR is a key element, since a residual inflammation, demonstrated by late gadolinium enhancement of pericardium, could suggest therapeutic chances of constriction reversal with proper anti-inflammatory treatment [38]. It has been recently demonstrated that a CMR-guided therapeutic strategy not only allows a reduced number of further recurrences, but also a minor use of corticosteroids [39].

CT allows the identification of pericardial inflammation by the presence of increased contrast-enhancement after iodinated contrast media administration and a thickened pericardium. In case of chronic constrictive pericarditis, pericardial membrane may display a variable degree of calcifications on CT. Furthermore, not only CT may show the presence of pericardial effusion, but the analysis of attenuation values may help in the differentiation of a transudative fluid ( $<10$ Hounsfield units) from an exudative fluid (20-60 Hounsfield units), which is typically present in case of purulent pericarditis [22, 31, 40]. 
A recent study proved the usefulness of [18F]-2-deoxy2-fluoro-d-glucose (FDG) Positron Emission TomographyComputed Tomography (PET/CT). In fact, in patients with acute pericarditis and pericardial effusion, an increased $18 \mathrm{~F}-$ FDG uptake of the pericardium was a risk factor for further recurrences [41].

\section{Therapeutic strategies}

Aspirin or nonsteroidal anti-inflammatory drugs (NSAIDs) in association with colchicine are the first-step approach [10] (Table 2; Fig. 3). However, if the diagnostic assessment reveals a non-idiopathic cause of pericarditis, the treatment should be causal, while conventional anti-inflammatory therapy is added on top. Exercise restriction is critical to relieve pericardial inflammation, since it may be a trigger of relapses, possibly due to an increased pericardial friction associated with higher heart rate $[5,42]$.

Colchicine, an ancient drug with increasing applications in the setting of cardiovascular diseases [43], has a key role in the inhibition of pericardial inflammation. Its use in the setting of pericarditis was first reported in a study in 1991 [44], while only later the COlchicine for acute Pericarditis (COPE) trial and Investigation on Colchicine for Acute Pericarditis (ICAP) trial proved a strong effect in the reduction of recurrences [7, 8]. In a recent study by Sambola et al. neutral effects were reported in 110 patients with acute pericarditis treated with colchicine. However, the authors specified that statistical power may have been hampered by the low rate of recurrences. In addition, they did not consider pericardial effusion as a diagnostic criteria and excluded patients who received corticosteroids. The use of colchicine for recurrent pericarditis was proved in the COlchicine for
REcurrent pericarditis (CORE) [2], Colchicine for Recurrent Pericarditis (CORP) [3] and COlchicine for Recurrent Pericarditis-2 (CORP-2) [4] studies, with a nearly half incidence of further pericardial flares in treated patients. Colchicine is associated with dose-dependent gastrointestinal side effects (mostly diarrhea) in about $8-10 \%$ patients. However, this usually does not affect compliance and is less frequent when colchicine is started without a loading dose [45]. In addition, a recent metanalysis by our group showed that the risk of gastrointestinal side effects may be avoided with a lower dose $(0.5 \mathrm{mg} / \mathrm{daily})$ [46]. The usual daily dose of colchicine is $0.5 \mathrm{mg}$ twice daily in patients with body weight greater than $70 \mathrm{~kg}$. A reduced dose of $0.5 \mathrm{mg}$ once daily is suggested in patients $<70 \mathrm{~kg}$, elderly ( $>70$ years), intolerant to higher dose or with impaired renal function (eGFR $35-49 \mathrm{ml} / \mathrm{min}$ ) [47].

Corticosteroids have been associated with an increased risk of recurrences $(R R=2.89)$, with a dose-dependent effect $[2,48]$. However, lower doses (e.g., prednisone $0.2-0.5 \mathrm{mg}$ / $\mathrm{kg}$ daily) are safer and indicated even as a first-line treatment in specific situations, such as renal failure, pregnancy, oral anticoagulants, autoimmune diseases requiring corticosteroid treatment, contraindications to aspirin and NSAIDs $[49,50]$. Although many doubts have been recently raised about the possible harms of anti-inflammatory therapies for COVID-19 associated pericarditis, there is no consistent evidence against conventional treatments, which should be offered anyway [51].

Despite treated with variable associations of aspirin or NSAIDs, colchicine and corticosteroids, some patients (about 5\%) may complain of persistent symptoms, commonly worsening when the dose of corticosteroids is decreased under a critical threshold [38, 52]. These patients, with corticosteroid-dependent and colchicine-resistant
Fig. 3 Therapeutic management of patients with recurrent pericarditis

\section{First line \\ Aspirin or NSAID + colchicine}

Second line

Corticosteroids + colchicine

Third line Aspirin or NSAID + colchicine + corticosteroids (triple therapy)

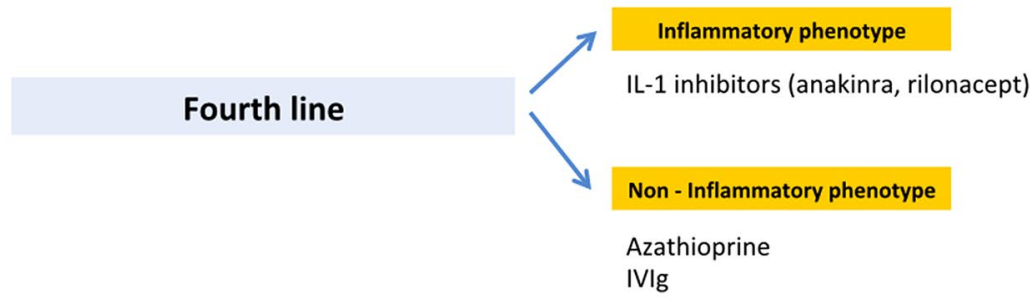

Fifth line

Pericardiectomy 
recurrent pericarditis, are the most challenging to deal with. A teamwork approach involving cardiologists, rheumatologists, clinical immunologists and internists is essential in these patients, to delineate further diagnostic and therapeutic strategies [53].

\section{Targeted approach to corticosteroid-dependent and colchicine-resistant recurrent pericarditis}

In case of corticosteroid-dependent and colchicine-resistant recurrent pericarditis, fourth-line treatments to be considered include immunosuppressive agent (i.v. immunoglobulins-IvIG, azathioprine) and anti IL-1 agents (e.g., anakinra, rilonacept).

Azathioprine is an immunosuppressive agent, whose use in this setting may allow corticosteroids reduction or withdrawal, although limited by a weak effect in the acute phase and a stronger effect in the long-term [54]. IvIG are particularly effective in case of a concurrent autoimmune disease. However, they require in vein administration, therefore, requiring hospitalization. Their use is additionally hampered by limited evidences reported in literature $[49,55]$.

A recent study by Lazaros et al. showed that in these patients hydroxychloroquine, acting through inhibition of autophagy in neutrophils, allowed significant corticosteroid dose reduction and increased flare-free survival compared to standard of care treatment, although did not reduce pericarditis recurrences [56].

Anakinra is a IL- 1 receptor antagonist, acting as an immuno-modulator at doses of $1-2 \mathrm{mg} / \mathrm{kg}$ daily with subcutaneous injection (maximum $100 \mathrm{mg} /$ day) [57]. Its efficacy in the reduction of further recurrences was first demonstrated in the AIRTRIP trial on 21 patients, with a lower incidence rate of pericarditis of 0.11 year-patient (versus 2.06/year-patient in patients receiving placebo) [58]. Furthermore, it allowed faster symptoms relief and corticosteroid withdrawal. These results were later confirmed in the larger and multicenter IRAP study, showing not only a marked reduction of recurrences, but also a lower rate of ED admissions and hospitalizations [9]. Moreover, in a recent study by our group, anakinra proved useful in the reversal of pericardial constriction [29]. Anakinra is not associated with serious adverse events, although transient skin reactions are commonly observed in about $1 / 3$ patients during the first month of treatment [9]. Canakimumab is an anti-IL1 $\beta$ monoclonal antibody with a long half life of more than 22 days, given at a fixed dosage of $150 \mathrm{mg} / \mathrm{month}$. It has a limited use because of high costs; however, in some cases, it has been used successfully in patients intolerant or allergic to anakinra $[59,60]$.
Rilonacept is an IL-1 decoy receptor, requiring a weekly administration. Its efficacy and safety has been demonstrated in the RHAPSODY multicenter trial [61].

Pericardiectomy should be considered as a last alternative in patients with chronic constriction or pericarditis with untreatable symptoms. Its efficacy is limited in case of post-cardiac injury etiology, advanced age or non-radical pericardiectomy, and burdened by a $5-10 \%$ perioperative mortality [62].

After the first episode of pericardial inflammation, a chronic low-grade inflammation is established and further sustained by auto-reactive processes in predisposed patients [38]. In this context, clinically evident recurrences may be triggered by a broad spectrum of infective or non-infective triggers, causing the re-activation of the inflammatory cascade, finally leading to recurrent symptoms. The precise mechanisms underlying this phenomenon are currently not fully elucidated [63]. However, an auto-inflammatory response based on interleukin-1 (IL-1) overproduction might be hypotesized in patients presenting with a typical "inflammatory phenotype" (fever and C-reactive protein elevation). On the contrary, an auto-immune response based on type I interferon pathway, might be prevalent in patients with concurrent auto-immune systemic disease, presenting with a non-inflammatory phenotype [38, 64-66]. A third clinical phenotype includes patients with subacute presentation and mild increase of inflammation markers, without autoimmune manifestations [67]. In a patient with recurrent pericarditis presenting with an inflammatory phenotype, a IL-1 inhibition-based strategy would be appropriate. In case of a non-inflammatory phenotype, if an autoimmune disease is recognized IvIG could be useful, otherwise azathioprine may be beneficial.

In conclusion, advanced diagnostic tools should be adopted for the early and accurate detection of recurrent pericarditis, while a targeted use of modern biologic drugs and other advanced treatments will further improve the outcomes in these patients.

Author contributions AA: article drafting, critical revision and approval of the final version. MI: article drafting, critical revision and approval of the final version.MC: critical revision and approval of the final version. SA: critical revision and approval of the final version. $\mathrm{AB}$ : critical revision and approval of the final version.

\section{Compliance with ethical standards}

Conflict of interest MI, AB Advisory Board for KINIKSA and SOBI, others: none.

Human and animal rights This article does not contain any studies with human particlipants or animals performed by any of the authors.

Informed consent For this type of study, formal consent is not required. 


\section{References}

1. Spodick DH (2003) Acute pericarditis: current concepts and practice. JAMA 289:1150-1153

2. Imazio M, Bobbio M, Cecchi E, Demarie D, Pomari F, Moratti M, Ghisio A, Belli R, Trinchero R (2005) Colchicine as firstchoice therapy for recurrent pericarditis: results of the CORE (COlchicine for REcurrent pericarditis) trial. Arch Intern Med 165:1987-1991

3. Imazio M, Brucato A, Cemin R, Ferrua S, Belli R, Maestroni $\mathrm{S}$, Trinchero R, Spodick DH, Adler Y, CORP (COlchicine for Recurrent Pericarditis) Investigators (2011) Colchicine for recurrent pericarditis (CORP): a randomized trial. Ann Intern Med 155:409-414

4. Imazio M, Belli R, Brucato A, Cemin R, Ferrua S, Beqaraj F, Demarie D, Ferro S, Forno D, Maestroni S, Cumetti D, Varbella F, Trinchero R, Spodick DH, Adler Y (2014) Efficacy and safety of colchicine for treatment of multiple recurrences of pericarditis (CORP-2): a multicentre, double-blind, placebo-controlled, randomised trial. Lancet 383:2232-2237

5. Soler-Soler J, Sagristà-Sauleda J, Permanyer-Miralda G (2004) Relapsing pericarditis. Heart 90:1364-1368

6. Imazio M, Trinchero R, Shabetai R (2007) Pathogenesis, management, and prevention of recurrent pericarditis. J Cardiovasc Med (Hagerstown) 8:404-410

7. Imazio M, Bobbio M, Cecchi E, Demarie D, Demichelis B, Pomari F, Moratti M, Gaschino G, Giammaria M, Ghisio A, Belli $\mathrm{R}$, Trinchero R (2005) Colchicine in addition to conventional therapy for acute pericarditis: results of the COlchicine for acute PEricarditis (COPE) trial. Circulation 112:2012-2016

8. Imazio M, Brucato A, Cemin R, Ferrua S, Maggiolini S, Beqaraj F, Demarie D, Forno D, Ferro S, Maestroni S, Belli R, Trinchero R, Spodick DH, Adler Y, ICAP Investigators (2013) A randomized trial of colchicine for acute pericarditis. N Engl J Med 369:1522-1528

9. Imazio M, Andreis A, De Ferrari GM, Cremer PC, Mardigyan V, Maestroni S, Luis SA, Lopalco G, Emmi G, Lotan D, Marcolongo R, Lazaros G, De Biasio M, Cantarini L, Dagna L, Cercek AC, Pivetta E, Varma B, Berkson L, Tombetti E, Iannone F, Prisco D, Caforio ALP, Vassilopoulos D, Tousoulis D, De Luca G, Giustetto C, Rinaldi M, Oh JK, Klein AL et al (2020) Anakinra for corticosteroid-dependent and colchicine-resistant pericarditis: The IRAP (International Registry of Anakinra for Pericarditis) study. Eur J Prev Cardiol. 27(9):956-964

10. Adler Y, Charron P, Imazio M, Badano L, Barón-Esquivias G, Bogaert J, Brucato A, Gueret P, Klingel K, Lionis C, Maisch B, Mayosi B, Pavie A, Ristic AD, Sabaté Tenas M, Seferovic P, Swedberg K, Tomkowski W, ESC Scientific Document Group (2015) 2015 ESC Guidelines for the diagnosis and management of pericardial diseases: The Task Force for the Diagnosis and Management of Pericardial Diseases of the European Society of Cardiology (ESC) Endorsed by: The European Association for Cardio-Thoracic Surgery (EACTS). Eur Heart J 36:2921-2964

11. Imazio M, Gaita F, LeWinter M (2015) Evaluation and treatment of pericarditis: a systematic review. JAMA 314:1498-1506

12. Imazio M, Brucato A, Derosa FG, Lestuzzi C, Bombana E, Scipione F, Leuzzi S, Cecchi E, Trinchero R, Adler Y (2009) Aetiological diagnosis in acute and recurrent pericarditis: when and how. $\mathrm{J}$ Cardiovasc Med (Hagerstown) 10:217-230

13. Imazio $M$ (2011) Pericardial involvement in systemic inflammatory diseases. Heart 97:1882-1892

14. Imazio M, Hoit BD (2013) Post-cardiac injury syndromes. An emerging cause of pericardial diseases. Int J Cardiol 168:648-652

15. Refaat MM, Katz WE (2011) Neoplastic pericardial effusion. Clin Cardiol 34:593-598
16. Imazio M, Cecchi E, Demichelis B, Ierna S, Demarie D, Ghisio A, Pomari F, Coda L, Belli R, Trinchero R (2007) Indicators of poor prognosis of acute pericarditis. Circulation 115:2739-2744

17. Lazaros G, Antonopoulos AS, Lazarou E, Vlachopoulos C, Vogiatzi G, Vassilopoulos D, Tousoulis D (2021) Age and sexbased differences in patients with acute pericarditis. Eur. J Clin Invest. 51:e13392

18. Sreenivasan J, Khan MS, Hooda U, Khan SU, Aronow WS, Mookadam F, Krasuski RA, Cooper HA, Michos ED, Panza JA. Rate, Causes, and Predictors of 30-Day Readmission Following Hospitalization for Acute Pericarditis. Am J Med. 2020;133(12):1453-1459.e1

19. Lange RA, Hillis LD (2004) Clinical practice. Acute pericarditis. N Engl J Med 351:2195-2202

20. Little WC, Freeman GL (2006) Pericardial disease. Circulation 113:1622-1632

21. Imazio M. Le malattie del pericardio. Diagnosi e terapia. Il Pensiero Scientifico Editore; 2016.

22. Imazio M, Gaita F (2015) Diagnosis and treatment of pericarditis. Heart 101:1159-1168

23. Farand P, Bonenfant F, Belley-Côté EP, Tzouannis N (2010) Acute and recurring pericarditis: More colchicine, less corticosteroids. World J Cardiol 2:403-407

24. Kytö V, Sipilä J, Rautava P (2014) Clinical profile and influences on outcomes in patients hospitalized for acute pericarditis. Circulation 130:1601-1606

25. Imazio M, Brucato A, Maestroni S, Cumetti D, Belli R, Trinchero R, Adler Y (2011) Risk of constrictive pericarditis after acute pericarditis. Circulation. 124:1270-5

26. Krasic S, Prijic S, Ninic S, Borovic R, Petrovic G, Stajevic M, Nesic D, Dizdarevic I, Djordjevic N, Vukomanovic V. Predictive factors of recurrence after pediatric acute pericarditis. J Pediatr (Rio J). 2020;29:S0021-7557(20)30190-X.

27. Imazio M, Colopi M, De Ferrari GM (2020) Pericardial diseases in patients with cancer: contemporary prevalence, management and outcomes. Heart 106:569-574

28. Avondo S, Andreis A, Casula M, Imazio M. Update on diagnosis and management of neoplastic pericardial disease. Expert Rev Cardiovasc Ther. 2020;18:615-623

29. Andreis A, Imazio M, Giustetto C, Brucato A, Adler Y, Ferrari GMD. Anakinra for constrictive pericarditis associated with incessant or recurrent pericarditis. Heart. 2020;106:1561-1565

30. Imazio M, Brucato A, Spodick DH, Adler Y (2014) Prognosis of myopericarditis as determined from previously published reports. J Cardiovasc Med (Hagerstown) 15:835-839

31. Klein AL, Abbara S, Agler DA, Appleton CP, Asher CR, Hoit B, Hung J, Garcia MJ, Kronzon I, Oh JK, Rodriguez ER, Schaff HV, Schoenhagen P, Tan CD, White RD (2013) American Society of Echocardiography clinical recommendations for multimodality cardiovascular imaging of patients with pericardial disease: endorsed by the Society for Cardiovascular Magnetic Resonance and Society of Cardiovascular Computed Tomography. J Am Soc Echocardiogr 26:965-1012.e15

32. Lazaros G, Imazio M, Brucato A, Tousoulis D (2016) Untying the Gordian knot of pericardial diseases: a pragmatic approach. Hellenic J Cardiol 57:315-322

33. Xu B, Kwon DH, Klein AL (2017) Imaging of the pericardium: a multimodality cardiovascular imaging update. Cardiol Clin 35:491-503

34. Fowler NO (1990) Recurrent pericarditis. Cardiol Clin 8:621-626

35. Imazio M, Demichelis B, Parrini I, Cecchi E, Pomari F, Demarie D, Gaschino G, Ghisio A, Belli R, Trinchero R (2004) Recurrent pain without objective evidence of disease in patients with previous idiopathic or viral acute pericarditis. Am J Cardiol 94:973-975 
36. Imazio M, Pivetta E, Palacio Restrepo S, Sormani P, Pedrotti P, Quarta G, Brucato A, Bubbico E, Dal Corso M, Milazzo A, Quattrocchi G, Andriani M, Lobetti Bodoni L, Davini O, Sironi S, Giannattasio C, Giustetto C, Bogaert J, Adler Y, Bucciarelli Ducci C, De Ferrari GM (2020) Usefulness of cardiac magnetic resonance for recurrent pericarditis. Am J Cardiol 125:146-151

37. Kumar A, Sato K, Yzeiraj E, Betancor J, Lin L, Tamarappoo BK, Kwon DH, Hachamovitch R, Klein AL (2017) Quantitative pericardial delayed hyperenhancement informs clinical course in recurrent pericarditis. JACC Cardiovasc Imaging 10:1337-1346

38. Cremer PC, Kumar A, Kontzias A, Tan CD, Rodriguez ER, Imazio M, Klein AL (2016) Complicated pericarditis: understanding risk factors and pathophysiology to inform imaging and treatment. $\mathrm{J}$ Am Coll Cardiol 68:2311-2328

39. Alraies MC, AlJaroudi W, Yarmohammadi H, Yingchoncharoen T, Schuster A, Senapati A, Tariq M, Kwon D, Griffin BP, Klein AL (2015) Usefulness of cardiac magnetic resonance-guided management in patients with recurrent pericarditis. Am J Cardiol 115:542-547

40. Imazio M, Gaita F (2017) Acute and recurrent pericarditis. Cardiol Clin 35:505-513

41. Gerardin C, Mageau A, Benali K, Jouan F, Ducrocq G, Alexandra J-F, van Gysel D, Papo T, Sacre K (2018) Increased FDG-PET/ CT pericardial uptake identifies acute pericarditis patients at high risk for relapse. Int J Cardiol 271:192-194

42. LeWinter MM (2014) Clinical practice. Acute pericarditis. N Engl J Med 371:2410-2416

43. Andreis A, Imazio M, De Ferrari GM. Colchicine for the treatment of cardiovascular diseases: old drug, new targets. J Cardiovasc Med (Hagerstown) 2020;

44. Millaire A, Ducloux G (1991) Treatment of acute or recurrent pericarditis with colchicine. Circulation. 1991;83:1458-9.

45. Imazio M, Brucato A, Belli R, Forno D, Ferro S, Trinchero R, Adler Y (2014) Colchicine for the prevention of pericarditis: what we know and what we do not know in 2014 - systematic review and meta-analysis. J Cardiovasc Med (Hagerstown) 15:840-846

46. Andreis A, Imazio M, Avondo S, Casula M, Paneva E, Piroli F, De Ferrari GM. Adverse events of colchicine for cardiovascular diseases: a comprehensive meta-analysis of 14188 patients from 21 randomized controlled trials. J Cardiovasc Med (Hagerstown) $2021 ; 21$.

47. Imazio M, Brucato A, Trinchero R, Spodick D, Adler Y (2009) Colchicine for pericarditis: hype or hope? Eur Heart J. 2009;30:532-9.

48. Imazio M, Brucato A, Cumetti D, Brambilla G, Demichelis B, Ferro S, Maestroni S, Cecchi E, Belli R, Palmieri G, Trinchero R (2008) Corticosteroids for recurrent pericarditis: high versus low doses: a nonrandomized observation. Circulation 118:667-671

49. Imazio M, Adler Y, Charron P (2016) Recurrent pericarditis: modern approach in 2016. Curr Cardiol Rep 18:50

50. Imazio M, Adler Y (2013) Treatment with aspirin, NSAID, corticosteroids, and colchicine in acute and recurrent pericarditis. Heart Fail Rev 18:355-360

51. Imazio M, Brucato A, Lazaros G, Andreis A, Scarsi M, Klein A, De Ferrari GM, Adler Y (2020) Anti-inflammatory therapies for pericardial diseases in the COVID-19 pandemic: safety and potentiality. J Cardiovasc Med 21:625-629

52. Lazaros G, Antonatou K, Vassilopoulos D (2017) The therapeutic role of interleukin-1 inhibition in idiopathic recurrent pericarditis: current evidence and future challenges. Front Med (Lausanne) 4:78

53. Brucato A, Emmi G, Cantarini L, Di Lenarda A, Gattorno M, Lopalco G, Marcolongo R, Imazio M, Martini A, Prisco D (2018) Management of idiopathic recurrent pericarditis in adults and in children: a role for IL-1 receptor antagonism. Intern Emerg Med $13: 475-489$
54. Vianello F, Cinetto F, Cavraro M, Battisti A, Castelli M, Imbergamo S, Marcolongo R (2011) Azathioprine in isolated recurrent pericarditis: a single centre experience. Int J Cardiol 147:477-478

55. del Fresno MR, Peralta JE, Granados MÁ, Enríquez E, Domínguez-Pinilla N, de Inocencio J (2014) Intravenous immunoglobulin therapy for refractory recurrent pericarditis. Pediatrics 134:e1441-1446

56. Lazaros G, Antonopoulos AS, Antonatou K, Skendros P, Ritis K, Hadziyannis E, Lazarou E, Leontsinis I, Simantiris S, Vlachopoulos C, Tousoulis D, Vassilopoulos D (2020) Hydroxychloroquine for colchicine-resistant glucocorticoid-dependent idiopathic recurrent pericarditis: a pilot observational prospective study. Int J Cardiol 311:77-82

57. Tombetti E, Mulè A, Tamanini S, Matteucci L, Negro E, Brucato A, Carnovale C (2020) Novel pharmacotherapies for recurrent pericarditis: current options in 2020. Curr Cardiol Rep 22:59

58. Brucato A, Imazio M, Gattorno M, Lazaros G, Maestroni S, Carraro M, Finetti M, Cumetti D, Carobbio A, Ruperto N, Marcolongo R, Lorini M, Rimini A, Valenti A, Erre GL, Sormani MP, Belli R, Gaita F, Martini A (2016) Effect of anakinra on recurrent pericarditis among patients with colchicine resistance and corticosteroid dependence: the AIRTRIP randomized clinical trial. JAMA 316:1906-1912

59. Epçaçan S, Sahin S, Kasapcopur O (2019) Anaphylactic reaction to anakinra in a child with steroid-dependent idiopathic recurrent pericarditis and successful management with canakinumab. Cardiol Young 29:549-551

60. Kougkas N, Fanouriakis A, Papalopoulos I, Bertsias G, Avgoustidis N, Repa A, Sidiropoulos P (2018) Canakinumab for recurrent rheumatic disease associated-pericarditis: a case series with long-term follow-up. Rheumatology (Oxford) Oxford Academic 57:1494-1495

61. Klein AL, Imazio M, Brucato A, Cremer P, LeWinter M, Abbate A, Lin D, Martini A, Beutler A, Chang S, Fang F, Gervais A, Perrin R, Paolini JF (2020) RHAPSODY: rationale for and design of a pivotal phase 3 trial to assess efficacy and safety of rilonacept, an interleukin- $1 \alpha$ and interleukin- $1 \beta$ trap, in patients with recurrent pericarditis. Am Heart J 228:81-90

62. Khandaker MH, Schaff HV, Greason KL, Anavekar NS, Espinosa RE, Hayes SN, Nishimura RA, Oh JK (2012) Pericardiectomy vs medical management in patients with relapsing pericarditis. Mayo Clin Proc 87:1062-1070

63. Andreis A, Imazio M, de Ferrari GM (2019) Contemporary diagnosis and treatment of recurrent pericarditis. Expert Rev Cardiovasc Ther 17:817-826

64. Karatolios K, Pankuweit S, Richter A, Ruppert V, Maisch B (2016) Anticardiac antibodies in patients with chronic pericardial effusion. Dis Markers 2016:9262741

65. Caforio ALP, Brucato A, Doria A, Brambilla G, Angelini A, Ghirardello A, Bottaro S, Tona F, Betterle C, Daliento L, Thiene G, Iliceto S (2010) Anti-heart and anti-intercalated disk autoantibodies: evidence for autoimmunity in idiopathic recurrent acute pericarditis. Heart 96:779-784

66. Jara Calabuig I, Sánchez Soriano RM, Marco Domingo TF, Pérez Ortiz C, Chamorro Fernández AJ, Chamorro Fernández CI (2017) Recurrent pericarditis as the presenting form of adult still's disease. Rev Esp Cardiol 70:208-209

67. Lopalco G, Rigante D, Cantarini L, Imazio M, Lopalco A, Emmi G, Venerito V, Fornaro M, Frediani B, Nivuori M, Brucato A, Iannone $\mathrm{F}$. The autoinflammatory side of recurrent pericarditis: Enlightening the pathogenesis for a more rational treatment. Trends Cardiovasc Med 2020;

Publisher's Note Springer Nature remains neutral with regard to jurisdictional claims in published maps and institutional affiliations. 